\title{
ANÁLISE DA ÁGUA PRECIPITÁVEL E DOS FLUXOS DE CALOR LATENTE/SENSÍVEL NO INÍCIO DA ESTAÇÃO CHUVOSA DAS REGIÕES SUDESTE E CENTRO-OESTE DO BRASIL
}

\author{
Danielson J. D. Neves', Rayana S. Araújo', José. A. Aravéquia \\ 'Center for Weather Forecast and Climate Studies, National Institute for Space Research, Cachoeira \\ Paulista, Brazil \\ danielson.neves@cptec.inpe.br
}

\begin{abstract}
RESUMO
A estação chuvosa nas regiões Sudeste e Centro-Oeste do Brasil é o objeto de estudo da presente pesquisa, que incide sobre a caracterização das condições atmosféricas de umidade e fluxos de calor (latente e sensível) nos momentos que precedem o início das chuvas nessas regiões para o período 2000-2010. Dados de reanálise água precipitável da Climate Forcast Reanalysis System (CFSR) foram utilizados para identificar o início da estação chuvosa, usando a metodologia proposta por Zeng e Lu (2004). Esta metodologia utiliza o Índice Normalizado de Água Precipitável (NPWI), que identifica o instante em que ocorre o início da estação chuvosa, a partir do momento em que o índice superior ao limiar 0618. Esta data foi utilizada para observar a evolução dos fluxos de calor durante o início da estação chuvosa. Os resultados apontaram as datas para o início da estação chuvosa, perto das datas indicadas na literatura, durante a primavera, entre os meses de outubro e novembro, precedido por um aumento gradual na quantidade de água precipitável na atmosfera destas regiões, levando a uma diminuição do fluxo de calor sensível uma vez que a radiação solar atua principalmente para evaporar do que para aquecer as superfícies.
\end{abstract}

Palavras-chave: água precipitável, estação das chuvas, o fluxo de calor sensível, fluxo de calor latente.

\section{Analysis of precipitable water and latent/sensible heat flux at the beginning of the rainy season in the Southeast and Midwest of Brazil}

\begin{abstract}
The rainy season in the Southeast and Midwest regions of Brazil is the object of study of this research, which focuses on the characterization of the atmospheric conditions of moisture and heat fluxes (latent and sensible) in the moments preceding the onset of the rains on these regions for the period 2000-2010. Precipitable water reanalysis data of the "Climate Forcast System Reanalysis" (CFSR) were used to identify the beginning of the rainy season using the methodology proposed by Zeng and Lu (2004). This methodology uses the Normalized Precipitable Water Index (NPWI) which identifies the instant at which occurs the start of the rainy season from the time when the index exceeds the threshold 0,618 . These dates were used to observe the heat fluxes evolution during the onset of the rainy season. The results pointed dates to the beginning of the rainy season close to the dates indicated in the literature, during the spring between the months of October and November, preceded by a gradual increase in the amount of precipitable water in the atmosphere of these regions, leading to a decrease of the sensible heat flux once the solar radiation acts mainly to evaporate than to heat the surfaces.
\end{abstract}


Keywords: precipitable water, rainy season, sensible heat flux, latent heat flux

\section{INTRODUÇÃO}

As regiões Sudeste e Centro Oeste do Brasil são caracterizados por uma estação chuvosa extremamente demarcada e sensível a atuação de fenômenos climáticos de grande escala como ENOS e OMJ, visto que estes condicionam a qualidade da estação chuvosa, atrasando ou adiantando a mesma. Tais fenômenos, caso suas ocorrências sejam previstas com certa antecedência, possibilitam a minimização dos seus efeitos com planejamentos e ações adequadas. Foram feitos vários estudos para se determinar o início da estação chuvosa, consistindo num monitoramento das condições atmosféricas durante um determinado intervalo de tempo que permitisse detectar variações sazonais do valor precipitado ou baseado em séries climatológicas, caracterizar algumas variáveis (por ex.: radiação de onda longa emergente, vento em baixos níveis, água precipitável e fluxo de vapor de água) às quais pudessem ser atribuídos valores limiares, com o objetivo de servirem como índices que permitam a identificação das condições que configurem o início e fim da estação chuvosa. (ALVES et al., 2005; GAN e MOSCATI, 2003; KOUSKI, 1988; LIEBMAN et al., 2007; MARENGO et al., 2001). Segundo a literatura a estação chuvosa nessas regiões inicia durante a primavera entre os meses de Setembro e Novembro.

Variáveis de umidade, como água precipitável e transporte de umidade integrada verticalmente, podem revelar bastante sobre a definição da estação chuvosa. Os fluxos de calor sensível e latente são resultantes do processo de interação da radiação solar com a superfície e dependendo do teor de umidade do ar e do solo, são originados. O fluxo de calor latente é resultante da ação da radiação solar na evaporação de superfícies úmidas e transpiração das plantas enquanto o fluxo de calor sensível resulta do aquecimento das superfícies provocado pela radiação solar.

Estes fluxos de calor ocorrem próximos à superfície terrestre e exercem grande influência nos processos atmosféricos de ascensão da parcela de ar, formação de convecção e consequente geração de intensa precipitação (TAO e SIMPSON; 1991 citado por Silva(2012)).

Silva (2012) avaliou a influência dos fluxos de calor latente e sensível em superfície sobre a região Centro Oeste do Brasil durante o inicio e final da estação chuvosa e observou que nas pêntadas que antecedem o inicio da estação chuvosa a atmosfera começa a se desestabilizar através do elevado aquecimento diurno nas baixas camadas, o que intensifica os movimentos atmosféricos e propaga a umidade e o calor superficial para altos níveis da atmosfera e dá espaço para o desenvolvimento das células convectivas associadas ao início da estação chuvosa. Ou seja, os fluxos de calor sensível estão associados ao período que antecede o inicio da estação chuvosa e auxiliam no processo de instabilização atmosférica, já os fluxos de calor latente são responsáveis pela manutenção da convecção depois do inicio da estação chuvosa.

\section{OBJETIVO}

Este estudo almeja obter as datas mais prováveis do início das chuvas analisando os campos de umidade (água precipitável e convergência de umidade) e analisar a evolução dos fluxos de calor latente e sensível nos instantes que precedem o inicio da estação chuvosa, nas datas obtidas.

\section{MATERIAIS E MÉTODOS}


Foram utilizadas informações de água precipitável, fluxo de calor latente e sensível, componente zonal e meridional do vento em $850 \mathrm{hPa}$ e umidade específica, através dos dados de reanálise CFSR (da sigla em inglês do Climate Forcast System Reanalysis) na resolução espacial de $0,5^{\circ}$ x $0,5^{\circ}$ abrangendo a área das regiões Centro Oeste e Sudeste do Brasil, focos do presente estudo. O período de estudo compreende 10 anos, do ano 2000 a 2010, nos quais foi calculada a média diária climatológica para cada variável mencionada anteriormente e sobre esse valor médio diário climatológico foi desenvolvido o estudo.

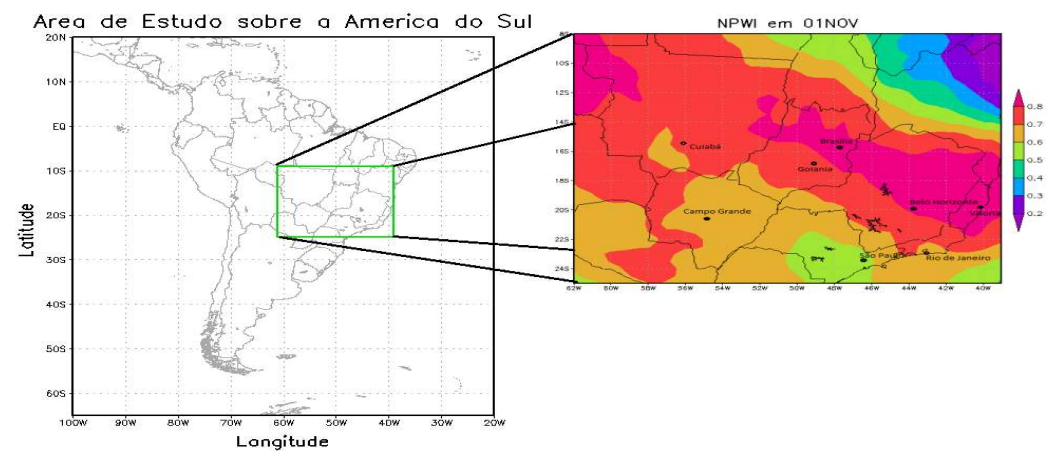

Figura 1. Localização da área de estudo enfocando a espacialização do Índice Normalizado de Água Precipitável (NPWI) nas regiões Sudeste e Centro Oeste do Brasil no dia 01 de Novembro.

Foi aplicada a metodologia desenvolvida por Zeng e Lu (2004) que consiste na normalização do valor diário de água precipitável, o qual gera um índice que serve como critério objetivo e de aplicação global para definir as datas de início e fim das monções. É descrito pela seguinte formulação:

$$
N P W I=\frac{P W-P W \min }{P W \max -P W m}
$$

onde PW (da sigla em inglês Precipitable Water) e água precipitável diária, PWmax e PWmin são os valores máximos e mínimos da média diária de água precipitável, no intervalo de anos considerados, em cada ponto de grade, ressaltando no caso do presente trabalho o uso de dados médios diários dos 10 anos estudados. E, por sua vez, PW que foi obtida através de dados de reanálise é calculado seguindo a formulação abaixo:

$$
W=\frac{1}{g} \int_{\text {Ptop }}^{\text {Psup }} q d p
$$

Os fluxos de calor sensível e latente foram obtidos através da reanálise CFSR, mas são calculados usando-se as seguintes formulações respectivamente:

$$
\mathrm{FCS}=\mathrm{C}_{\mathrm{p}} \rho \mathrm{C}_{\mathrm{DH}} \mathrm{U}_{\mathrm{r}}\left(\mathrm{T}_{\mathrm{s}}-\mathrm{T}_{\mathrm{a}}\left(\mathrm{Z}_{\mathrm{r}}\right)\right) \quad \text { (3) } \quad \mathrm{FCL}=\mathrm{L} \rho \mathrm{C}_{\mathrm{DE}} \mathrm{U}_{\mathrm{r}}\left(\mathrm{q}_{\mathrm{s}}-\mathrm{q}_{\mathrm{a}}\left(\mathrm{Z}_{\mathrm{r}}\right)\right)
$$

\section{RESULTADOS}

O cálculo do Índice Normalizado de Água Precipitável seguindo a metodologia de Zeng e Lu (2004), descrita anteriormente, foi efetuado para toda a área de estudo, no entanto foram plotados os gráficos de linha (Figura 2) referentes à evolução desse índice para apenas alguns locais considerados importantes em função da localização de grandes cidades e hidrelétricas, pois não seria cabível no trabalho a plotagem da evolução 
temporal do índice em cada ponto de grade. O que se vê nos gráficos é evolução da média de área $\left(2^{\circ} \times 2^{\circ}\right)$ do índice e de forma geral observou-se que a estação chuvosa inicia entre Outubro e Novembro na maior parte da área de estudo, quando o valor do índice supera o limiar de 0,618. Na região Centro-Oeste nota-se que os fluxos de calor têm uma evolução contraria, na estação seca o fluxo de calor sensível aumenta enquanto o fluxo de calor latente diminui, mas nos dias que antecedem o inicio da estação chuvosa essa tendência se altera, tendo o fluxo de calor latente um aumento gradativo enquanto o fluxo de calor sensível decresce na mesma proporção. Quando as curvas desses dois fluxos se cruzam têm-se a transição da estação seca para a estação chuvosa onde o fluxo de calor latente vai dominar em consequência da grande disponibilidade de umidade a ser evaporada, resultante das chuvas.

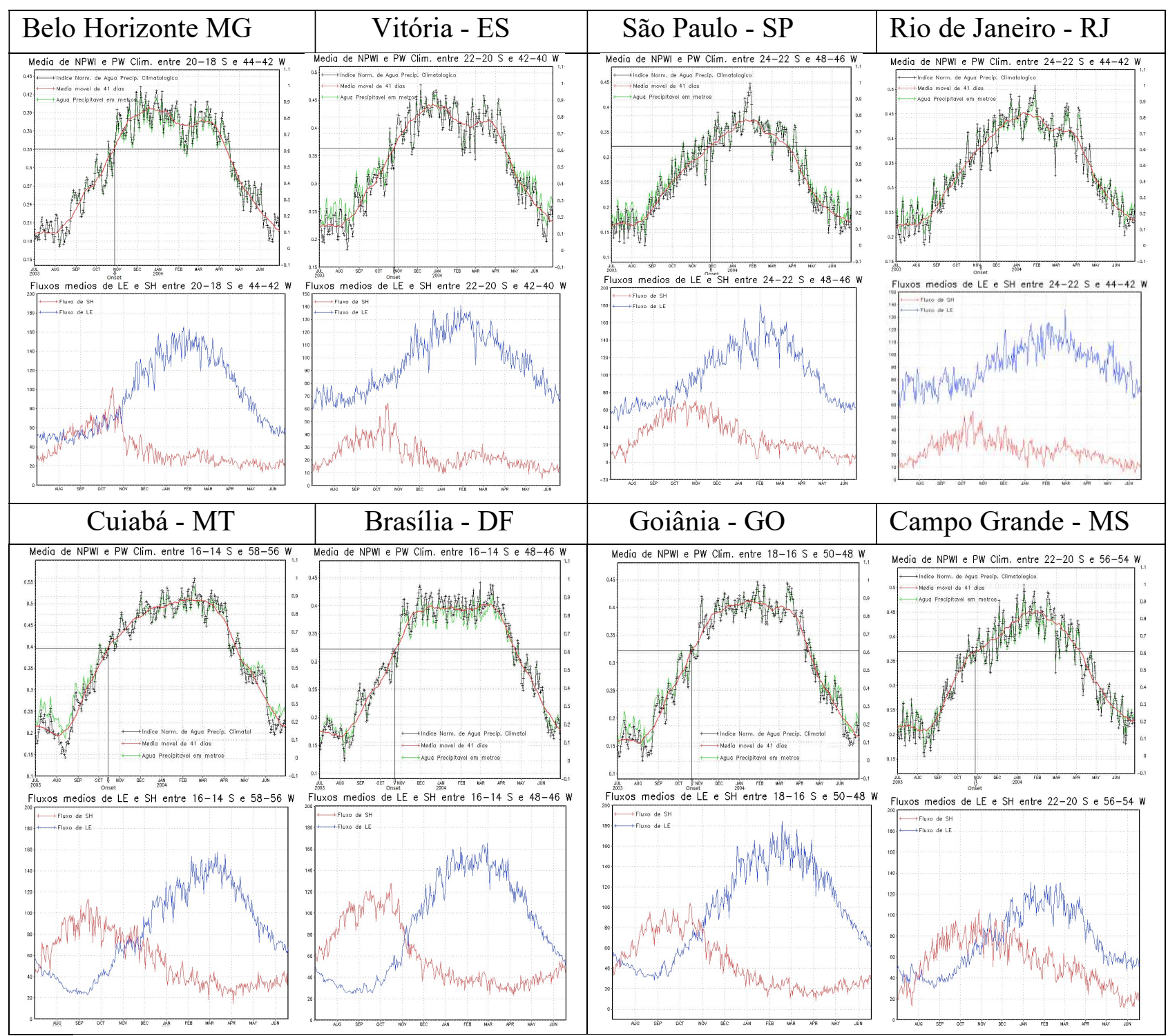

Figura 2. Evolução temporal da água precipitável, do NPWI com a sua média móvel de 41 dias correspondente e dos fluxos de calor para diferentes áreas da região Sudeste e Centro Oeste $\left(2^{\circ} \mathrm{x}\right.$ $\left.2^{\circ}\right)$. 


\section{CONCLUSÕES}

A estação chuvosa inicia, em média, na metade de Outubro na região Centro Oeste e em meados de Novembro na região Sudeste.

A circulação de grande escala em resposta ao aquecimento gradual (fluxo de calor sensível elevado) do hemisfério sul, a partir dos meses de Agosto/Setembro, leva ao aumento no transporte de umidade para a região da bacia Amazônica e deste para a região centro oeste e finalmente para a região sudeste (retração da ASAS com posicionamento oceânico/jato de baixos níveis), aumentando o fluxo de calor latente e diminuindo o fluxo de calor sensível.

\section{REFERÊNCIAS BIBLIOGRÁFICAS}

Zeng, X.; Lu, E. Globally Unified Monsoon Onset and Retreat Indexes. Journal of Climate, 17, 2241-2248. 2004.

SILVA, A. B. Influência dos fluxos de calor em superfície no início e no final da estação chuvosa sobre a região centro-oeste do Brasil. Dissertação (Mestrado em Meteorologia) Instituto Nacional de Pesquisas Espaciais, São José dos Campos, 2012. xxxii +169 p.; (sid.inpe.br/mtc-m19/2012/08.15.18.09-TDI) 